\title{
AUTORAS AFRICANAS: A FAVOR DE LAS MUJERES
}

\author{
African authors: In favor of women
}

\author{
María Socorro Suárez Lafuente \\ lafuente@uniovi.es \\ Universidad de Oviedo - España
}

Recibido: $03-03-2017$

Aceptado: 05-06-2017

\section{Resumen:}

La cultura occidental produce binomios de poder fuertemente inscritos en el lenguaje y el imaginario colectivo. Las subversiones aparecen primero en la zona dominante, como el feminismo, que se extiende, posteriormente, a otros feminismos, igualmente lógicos y reivindicativos, pero con menos capacidad de visibilización en un mundo globalizado. Las mujeres de grupos minorizados que han conseguido acceder a la educación han levantado sus voces y utilizado su potencial creativo a favor de las silenciadas de su cultura, a las que no alcanzaban el feminismo blanco occidental. Amma Darko, Bessie Head y Chimamanda Ngozi Adichie son algunos de los nombres que encabezan un movimiento africano feminista, que prioriza la libertad individual de las mujeres y les hace sentirse orgullosas de ser africanas.

Palabras clave: Feminismos, literatura, diversidad, igualdad, equidad, empatía, convivencia solidaria.

\begin{abstract}
Western culture produces binaries of power that are deeply inscribed both in language and in the collective imaginarium. Subversions tend to appear in the more affluent class, as is the case with feminism, which later extend to other feminisms, equally important and vindicatory, but with fewer opportunities to become visible within a globalized world. Many women from minoritized groups have had access to education, have been able to use their creative force and have become the voice of many silent women who were not included in the successive waves of Western feminisms. Amma Darko, Bessie Head and Chimamanda Ngozi Adichie are but a few names at the forefront of African feminism, a movement that fights for the individual rights of women and makes them feel proud of their Africanism.
\end{abstract}

Keywords: Feminisms, literature, diversity, equality, equity, empathy, conviviality. 


\section{Planteamiento inicial: Espacios éticos}

Simone de Beauvoir en su Ética de la ambigüedad (1947: n.p.) cita estas palabras de Montaigne: "La vida no es, en sí, ni buena ni mala. Es el lugar de lo bueno y de lo malo, según cómo lo hagas"1. Esta frase explica, por sí sola, la responsabilidad personal; pero, mientras que los presupuestos éticos fundamentales parecen obvios y, por tanto, fáciles de cumplir, la socialización secular llevada a cabo en occidente nos arrastra a actuar únicamente desde las líneas marcadas por los poderes fácticos. Así pues, toda la historia de dinastías, guerras, conquistas y colonialismos, con sus barreras bien delimitadas entre buenos y malos, "los que están conmigo y los que están contra mí", ha hecho de nuestra cultura un lugar binario, donde pasar de un lugar a otro de la ecuación es extremadamente difícil.

Un espacio ético que diera lugar a la disolución de los binarismos sería el que propugna la "teoría de las cuencas hidrográficas" ("Watershed Theory", Cushman y Kovacic, 1995); es decir, un camino común en el que confluyen las diferentes maneras de ser y estar en el mundo y en el que se suman caudal humano y esfuerzos en busca del bienestar general. Pero el sentido de nación abonado por el lenguaje dominante convierte los espacios éticos prácticamente en imposibles. La nación viene definida por una frontera, un límite conceptual apoyado en una historia, una genealogía, una religión y unos mitos y costumbres a los que se adjetiva como "comunes" y, por tanto, "oficiales". De ahí que el nacionalismo sea incluyente y, como consecuencia, excluyente; y el ser humano sabe, por la experiencia de su inconsciente colectivo, que es mejor estar dentro que estar fuera.

Si en un momento de la historia se e/migra, se convierte una en la alteridad, la otra raza, la otra etnia, la otra cultura. Y esa alteridad permanece a través de los tiempos si las marcas físicas de la otredad siguen siendo visibles, si el color de la piel es diferente respecto del de la norma del poder, es decir de la raza blanca, occidental y cristiana. El problema fundamental, como siempre, es el cuerpo y, sobre todo, el cuerpo de las mujeres: un cuerpo femenino que está sexualizado por la sociedad y al que se añade el componente racista (la invasión de mi nación) que exotiza lo que no comprende y le tiene miedo.

Así, se invisibiliza a la persona, su manera de ser, sus sentimientos, sus deseos, su planteamiento de futuro y sus motivaciones: se la convierte en un cuerpo deshumanizado y, por tanto, soporte de prejuicios y temores. Insisto en la importancia del miedo a lo diferente, a lo desconocido, y en la pobreza cultural e histórica de quienes lo sienten, porque sólo el desconocimiento abona la propia decadencia. Barbara Waldis analizó ya en 1998, la comunicación intercultural, y utilizó un término que explica muy acertadamente esta situación:

${ }^{1}$ La traducción es nuestra. 
el de "Gramática Monocultural", que implica que la cultura occidental traduce su historia, su arte, su cultura y los confines de su territorio en palabras masculinas, blancas, cristianas y de clase media. Pero, según las palabras, profusamente citadas, de Edward Said en Culture and Imperialism:

"No one today is purely one thing. [...] Yet just as human beings make their own history, they also make their cultures and ethnic identities. No one can deny the persisting continuities of long traditions, sustained habitations, national languages, and cultural geographies, but there seems no reason except fear and prejudice to keep insisting on their separation and distinctiveness, as if that was all human life was about" (1994: 408)².

Cualquier cambio en la estructura "tradicional" asusta, porque amenaza la integridad cultural, racial y patriarcal del poder. Para defenderse de tal amenaza, para seguir siendo un país empoderado, se transforma al otro en alteridad y a la otra en abyección (según término de Julia Kristeva). Poco importa que estas mujeres hablen el idioma bien, "sean útiles a la sociedad o tengan un pasaporte del lugar - ser diferentes les desautoriza para ser ciudadanas de pleno derecho" (Teo y Mecheril, 1994: 97).

La lengua se podría haber convertido en un remo común para "la cuenca ética", a pesar de que es un argumento débil. Pues si bien es cierto que la lengua, como dijo Fernando Lázaro Carreter, es el archivo adonde han ido a parar las experiencias, saberes y creencias de una comunidad, no es menos cierto que las experiencias, saberes y creencias de una comunidad están en continua mutación y que cada persona es el resultado de muchos genes diferentes. Recordemos de nuevo las palabras de Said: "No one today is purely one thing".

Lo que verdaderamente marca las diferencias, lo que atenúa la diferencia de la piel, es la clase social, y, siempre, en el escalón más bajo de la sociedad está la subalterna, quien, ya nos lo dijo Gayatri Spivak en 1988, es la mujer que no sabe que tiene derecho a tener derechos, que no tiene voz porque no ha tenido tiempo ni conocimientos para pensar que puede utilizarla. Por tanto, las autoras que voy a mencionar más adelante no son subalternas, tienen voz propia, genealogía, historia personal y subjetividad. Lo saben, han podido pensar y escribir, y utilizan sus capacidades para recabar sus derechos individuales y para acabar con la subalternidad de las mujeres diferentes.

En la década de 1970, las mujeres blancas occidentales definieron e inscribieron clara y tajantemente las líneas de su subversión integral: la ginocrítica, la teoría feminista y la reescritura de los textos fundacionales, de los cuentos maravillosos y de la historia. Esta apertura cultural permitió apreciar que había exclusiones notables, la de muchas mujeres "diferentes" que fueron

\footnotetext{
${ }^{2}$ El subrayado es nuestro.
} 
paulatinamente sumándose al nuevo movimiento y, como es lógico, lo modificaron y lo enriquecieron. Es oportuno recordar aquí a Michel Foucault:

"La formación del discurso no es un texto ideal, continuo, sin fisuras, que subyace a una multiplicación de contradicciones y las resuelve con su pensamiento coherente, unitario y aposentado. $\mathrm{Ni}$ es la superficie sobre la que se reflejan, de mil maneras diferentes, unas contradicciones que, aunque parecen difuminarse, están siempre presentes. La formación del discurso es un espacio de disensiones múltiples: un lugar en el que hay que inscribir las funciones y los niveles de actuación de diferentes oposiciones" $(2002: 217)^{3}$.

Un "discurso de disensiones múltiples" y de "funciones y niveles de actuación de diferentes oposiciones" habla, como es de rigor, de fragmentaciones culturales, de grupos minorizados y de multiculturalismos. Pero es también un discurso histórico que pretende poner en tela de juicio la idea de que tal enunciación, la de la nación, es coherente, continua, ideal, unitaria y aposentada. La deconstrucción está planteada ya desde hace casi medio siglo; diversas cabezas pensantes han incidido en que los discursos son procesos en los que se debaten intereses parciales, son espacios de construcciones interesadas, manipuladoras, que sólo se pueden entender admitiendo su dimensión parcial en el total de la disertación y su función relegada a un tiempo y un espacio. Pero, como decíamos hace unos párrafos, es muy difícil salvar los abismos de las diferencias.

En este último siglo de migraciones, de exilios y de refugiados, se han abierto infinitas posibilidades de argumentación que se debaten entre los extremos de los imposibles términos dicotómicos, lo bueno y lo malo, lo justo y lo injusto, etc. El conocimiento está diseminado a lo largo y ancho de la geografía cultural y humana, a través de las lenguas y las artes, y, como explicó Jacques Derrida en 1972, en su libro Dissemination, es responsabilidad de cada persona el recoger fragmentos e ir elaborando un pensamiento amplio y en desarrollo constante; la experiencia individual es básica para entender la cultura en que nos movemos, así podremos dar el paso hacia una riada cultural diversa y comunicativa, que contesta positivamente a la pregunta del poema "Rock Bottom" de Michael Ondaatje en The Cinnamon Peeler (1989: 402):

"The space in which we have dissolved -

does it taste of us?".

Es en esta disolución espacial, engendradora de diálogo, en donde se sitúan las voces de las autoras diversas, dispersas por la cartografía del tiempo y de la historia, que, con el fin común de la visibilidad y el empoderamiento de las mujeres, articulan las perspectivas feministas desde su conocimiento vital. Veamos algunos ejemplos.

\footnotetext{
${ }^{3}$ El subrayado es nuestro.
} 


\section{El difícil camino del auto-conocimiento}

Amma Darko nació en Ghana, donde vive en la actualidad, y residió en Alemania entre 1981 y 1987. Darko emigró atraída por la promesa del "sueño europeo" que corre por las venas sociales de los países africanos, y se fue a Alemania porque allí tenía la referencia de una 'amiga por correspondencia'. "Yo era joven, era libre, tenía hambre de conocimiento y quería establecerme como escritora. Pero, en realidad, más que escribir, lo que quería era salir de mis confines" (2007: 9). Darko escribió tres novelas y una colección de narraciones publicadas primero en Alemania, en alemán: Der verkaufte Traum (1991), Spinnweben (1996), Das Hausmädchen. Geschichten (1998) y Verirrtes Herz (2000). Ya en inglés y publicadas en África, escribió Faceless (2003), Not without Flowers (2006) y Between two Worlds (2015) y el libro de literatura juvenil: The Necklace of Tales (2015).

Siguiendo la lógica de lo que veíamos al principio de este artículo, los años que Darko pasó en Alemania cambiaron profundamente su visión del mundo y, por lo tanto, influyeron en la autora que llegó a ser. Entendió que Europa no era "la tierra prometida", que ser inmigrante es una dura experiencia, que ser inmigrante ilegal es una pesadilla, que ser mujer y negra es ser doblemente discriminada, que la gente blanca sólo ve a 'gente negra' y que ésta se convierte en culpable de todos los males sociales. Sus personajes sienten, por tanto, añoranza de su casa, aún reconociendo todos los (grandes) defectos que asolan a su país de origen, y se ven impelidos a defender sus valores y mejorar sus problemas.

Amma Darko, sus personajes, y otras personas de origen africano se plantean ¿Qué ha hecho África para merecer esto? ¿Hay alguna forma de cambiar el trato internacional que recibe? ¿Se puede modificar la opinión, gratuitamente negativa, de la gente occidental? Ante preguntas de tanto calado histórico e internacional, Darko, entre otros escritores, se decantó por inscribir los problemas de su entorno de los que tenía más conocimiento, los de los niños y los de las mujeres casadas, que son menores de edad a efectos sociales y políticos al ser consideradas un mero apéndice de sus esposos.

En Más allá del horizonte expone el sufrimiento de muchas mujeres 'diferentes' y 'exotizadas' en el mundo occidental. Mara, el personaje principal, sufre el despotismo y la crueldad de su marido tanto en Ghana como en Alemania. En una sociedad blanca, indiferente o desconfiada, el marido la empuja a la prostitución para su propio lucro porque es "demasiado ilegal y demasiado negra para un trabajo normal" (Darko, 2003: 160). Dice Amma Darko en una entrevista con Patrick Muana: "My stories, most of the time, reflect the reality and male hegemony which is manifested in various ways and forms in different cultures, societies and situations" (online). Más adelante, Darko explica: 


\begin{abstract}
"When my novel came out, many assumed it to be my personal experience. When they got to know me and realised that I couldn't be Mara, they set out on a search hunt for who Mara was in reality [...] She does not embody any one woman's life ... But I think that every aspect of her reflects someone's disposition and real life experience" (Muana, 2008: n.p.).
\end{abstract}

El sueño europeo se concreta bien en la idea utópica de la libertad democrática, bien en cosas puramente prácticas: "Mara, en un año, sólo en un año, tu misma lo verás. ¡Haré tanto dinero que podré comprar todo lo que queramos! ¡Una televisión, una radio, una nevera, una alfombra y hasta un coche!” (Darko, 2003: 53).

Para los que quedan en África tener parientes en Europa elevaba considerablemente su valor social, lo que supone un punto de presión más para quienes no están disfrutando del nuevo país. Esta es la experiencia de Mara, pues "De pronto, la gente saludaba a mi madre con reverencia y advertían a sus hijos que trataran a mis dos niños con respeto y con cuidado cuando jugaban [...] tal era la magia que tenía Europa" (Ibídem: 79). Es precisamente esta leyenda la que provoca el sacrificio final de Mara en Alemania, que entrega salud y vida por su familia africana, por su bienestar y por su buen nombre, puesto que volver pobre o enferma sería un síntoma de debilidad y traería la deshonra a su familia. Así, al final de la novela, está pagando con su sangre "la construcción de una gran casa de cemento en el pueblo para mi madre. Ahora la tienen en tal alta estima que incluso ha conseguido volver a conquistar a mi padre [...] y que busquen una casita de cemento en la ciudad que pueda comprarles a mis dos hijos" (Ibídem: 194).

Europa se concreta, efectivamente, en cosas materiales, pero falla a la hora de proveer afecto y empatía. El dolor y la muerte de una persona no blanca, no rica, no poderosa, no tiene el mismo valor que el de un hombre blanco cristiano. Ato Quayson analiza la situación de las mujeres africanas en "Feminism, Postcolonialism and the Contradictory Orders of Modernity" (2007) y asevera algo que es cierto de las mujeres en cualquier país. que "women's existence is strung between traditionalism and modernity in ways that make it extremely difficult for them to attain personal freedoms without severe sacrifices or compromises." (Citado en: Umezurike, 2015: $\left.155^{4}\right)$.

Cuando Mara, después de varios avatares en Alemania, se pregunta "por qué no podía asumir el control de mi propia vida si en definitiva era casi una mujer sin marido" (2003: 165) y ya sin dignidad, sabe que sólo podrá asumir el control de su vida, pero no el del uso de su cuerpo. La ‘cosificación' o reificación del cuerpo de las mujeres es la moneda de cambió más común, el sacrificio último del instinto humano de supervivencia. Cuando Mara comprende el valor social de su cuerpo, se sirve de él para su propio 'beneficio', en lo que Elizabeth Grosz denominó “un espacio de resistencia" un cuerpo marcado por la violencia de los demás, pero que "always entails the possibility of a counterstrategic reinscription, for it is capable of being self-marked, self-

\footnotetext{
${ }^{4}$ El subrayado es nuestro.
} 
represented in alternative ways" (Grosz, 1990: 64). El "despertar" europeo de Mara, su valor en términos de sexo, la destruye y la construye, en una paradoja insalvable. Umezurike lo define muy bien: "Mara remains a subject, powerless in her subjection by ideology" (1991: 158).

La autora egipcia, Nawal al Saadawi, hace recorrer al personaje principal de su novela Mujer en punto cero (1975) el mismo itinerario lógico que Mara. Firdaus sigue un camino de maltrato marcado por los hombres y por mujeres asimiladas al patriarcado: su padre primero, después su tío, la mujer de éste, su marido, el frutero, la madame y el proxeneta que la elije. Se trata de personajes masculinos embrutecidos que no piensan, sino que disfrutan, cual animales, de las prerrogativas que les concede el sistema. Cuando, a los 25 años, un hombre paga directamente a Firdaus por sus favores sexuales, que ella le había concedido por obligación, como estaba acostumbrada a hacer, Firdaus reconoce el valor del uso de su cuerpo y decide explotarlo con conocimiento de causa.

No es este un estado deseable, ni un fin en sí mismo, pero 'comprender' es el primer paso hacia la libertad interior. El dinero que le pagan por el uso de su cuerpo constituye para Firdaus su "habitación propia", un espacio para la definición del propio yo, fundamental para alcanzar la identidad que sustenta nuestra voluntad y nos integra en el feminismo al liberarnos de la subalternidad. El relato novelado de la vida de Firdaus contada por ella misma y recogido por al Saadawi no podía terminar bien en un mundo patriarcal, y la vida le empuja a matar para defender su derecho a elegir. Pero se enfrenta a su ejecución con el valor que confiere saber quién se es, de dónde se partió, qué se quiere y qué es lo que puede esperar.

Su autora, Nawal al Saadawi, médica, psiquiatra, escritora y feminista egipcia, ha trabajado toda su vida por los derechos humanos y por los derechos específicos de las mujeres, por la salud integral de las personas, basado en la educación y la erradicación de la pobreza. Esta dedicación social y política le ha valido la cárcel, la persecución y varias amenazas de muerte. Su amplia obra comprende novelas, narraciones breves, obras de teatro, libros de memorias, libros de medicina y libros de política y sociología; entre otros títulos: Memorias de una doctora (1960), Mujeres y sexo (1969), Mujer en punto cero (1975), Mujeres y neurosis en Egipto (1976), Prisión de mujeres (1982), La caída del imán (1987), Memorias de un niño llamado Soad (1990), La cara desnuda de la mujer árabe (1991), Ganat y el demonio (1991), Amor en el reino del petróleo (1993), Los papeles de mi vida (1995), La hija de Isis (2008), La novela (2004) y Zeina (2009).

\section{Otras pioneras}

Ni Nawal al Saadawi ni Amma Darko son casos aislados del feminismo de grupos minorizados. Desde principios del siglo XX varias mujeres egipcias lucharon, con su pluma, por la causa feminista; entre ellas se cuentan Aisha al Taymoureya, Zeinab Fawaz, Malak Hefin 
Nassif o Mai Ziada, que fundó un salón literario ya en 1915. Huda Shaarawi organizó el primer grupo feminista egipcio en 1923 y abogó por subir la edad para casar a las niñas y por la reforma de unas leyes matrimoniales totalmente lesivas para el derecho de las mujeres. Sus desvelos los inscribió en sus memorias Los años del harén: memorias de una feminista egipcia. 1879-1924, publicado póstumamente en 1987. En época contemporánea sobresalen Radwa Ashour, Miral al Tahawy, Ahdaf Soueif, Sabrina Mahfouz, Alifa Rifaat, Safaa Fathy o Iman Mersal, por mencionar a unas pocas. Salwa Bakr, que cuenta con una amplia obra literaria, da voz a las marginadas, a las mujeres pobres y, generalmente, analfabetas, abocadas a la subalternidad y, con demasiada frecuencia, a la cárcel. Al español ha sido traducida su colección de narraciones breves Las artimañas de los hombres de 1992.

Las mujeres africanas llevan décadas inscribiendo en su obra literaria los problemas cotidianos, políticos y sociales que le afectan negativamente ya desde la época precolonial. Sometidas, como todas las mujeres del mundo, a unas leyes estructurales patriarcales, las africanas han sido definidas a través de la oratura como mujeres fuertes, protectoras, cuidadoras y con una alta capacidad de trabajo, a la vez que les envuelve un halo de misterio, fruto del desconocimiento, que acentúa el miedo de la sociedad a que puedan salirse de la estructura prefijada. Se supone que su ámbito es meramente privado, pero sufren, en su vida y en su cuerpo, los avatares políticos, militares y religiosos de su entorno. Una de sus autoras más significativas, Ama Ata Aidoo (Ghana), afirma: "Traditionally, a woman is supposed to be nothing more valid than a mother. Sometimes one gets nervous of such total affirmation and total negation in relation to other roles that one has played" (James, 1990: 13).

A esta "nervous condition", como Tsitsi Dangarembga (Zimbabwe) la definía en 1988, también en relación con el añadido del desconocimiento de una lengua, unas creencias y unas leyes coloniales que la gente africana tardó, lógicamente, mucho en comprender, se añadía la situación política de las continuas luchas tribales, étnicas, coloniales y racistas que hacen a la autora sudafricana Lauretta Ngcobo exclamar:

"My community is so involved in a political struggle that expression of my society comes out mainly through politics taking a political angle. I would have loved to just write about things as they happen among my people, but there is no phase, no aspect of my social life that is not affected by the climate of politics in South Africa. South African writers don't choose their themes, they are chosen by the themes" (Andreu, 1987: 129).

A pesar de lo cual, las autoras no pueden sustraerse al problema elemental de su situación como mujeres; invisibilizadas socialmente por su propio entorno, son doblemente ignoradas por los poderes fácticos occidentales en el terreno de la literatura. De nuevo es Ama Ata Aidoo quien denuncia esta realidad con una reflexión muy acertada sobre la doble discriminación de las mujeres africanas, por ser mujeres y por ser africanas: "African women writers are just receiving 
the writer's version of the general neglect and disregard that women in the larger society receive [...] Bessie Head died of neglect. So how is she going to be an Achebe?" (James, 1990: 11-12).

Bessie Head fue una autora ubicada en un espacio cultural intermedio, hija de blanca y de negro, que siente los problemas del apartheid sudafricano en Botswana, desde donde escribe, y que escribe obras a medio camino entre la ficción y la autobiografía, entre la historia y la memoria. María Vidal dice de ella que no habla "of the injustices and absurdities intrinsic in apartheid society or of the police brutality in South Africa. She simply causes the reader to empathise with the trauma induced in the individual mind by racial hatred and sexist discrimination" (Vidal, 1989: 233). Uno de los pocos poemas que Head escribió, publicado en 1962 en el periódico The New African bajo el título "Things I don't like", condensa, en el siguiente fragmento, todas las quejas de las mujeres africanas:

\footnotetext{
"Soy negra.

¿Vale?

El sol ardiente y la situación geográfica

me hicieron negra;

y a causa de mi piel

me suceden muchas cosas

QUE NO ME GUSTAN.

$\mathrm{Y}$ despierto cada mañana

con ojos de asesina

porque algún estúpido me ha vuelto

a quitar de las manos lo poco que tenía

con todo el mundo a mi alrededor

mirando sin hacer nada...

¿Vale?

$[\ldots]$

Oh, no.

Hoy es mi día.

Voy a recuperar una por una

todo lo que me robasteis.

Voy a luchar contra ti hasta que tu o yo

caigamos machacados y desangrados

y no me importa quien muera, Tu o Yo.

Pero voy a luchar...

¿Vale? ${ }^{5 "}($ Head, 1962: 106).
}

\footnotetext{
${ }^{5}$ La traducción es nuestra.

${ }^{6} \mathrm{La}$ traducción es nuestra.
} 
La desesperación ante las fragrantes injusticias es una de las constantes de la literatura feminista; poco importan que las autoras se consideren feministas o no, cuando defienden la lógica de la igualdad social, cuando arremeten contra el absurdo de la inequidad, están añadiendo una tesela más al mosaico global de la integridad personal de las mujeres del mundo y animando a otras autoras a que, gota a gota, vayan desgranando su creatividad literaria en pos de un cambio en la estructura social.

Buchi Emecheta, Mariama Bâ, Efua Sutherland, Miriam Tlali, Ellen Kuzwayo, Sindine Magona, Boitumelo Mofokeng, Flora Nwapa, Véronique Tadjo, Aminatta Forna, NoViolet Bulawayo son sólo un exponente mínimo de las muchas escritoras negras, preocupadas por la situación de sus compatriotas, dispuestas a dar voz, en inglés, a los problemas con que se encuentran las mujeres en su país y a explicar los resortes de su cultura autóctona, en lo que se ha dado en llamar "conocimiento democrático", el conocimiento que "acknowledges the existence of multiple epistemologies or ways of knowing, including organic, spiritual and landbased systems, frameworks arising from social movements, and the knowledge of marginalised and excluded people everywhere" (Tandon y Hall, 2014: 2).

\section{Expectativas de futuro}

Chimamanda Ngozi Adichie, nigeriana, joven, con un título universitario, está concitando la atención del mundo académico y editorial, como portavoz de las mujeres africanas contemporáneas. Su emotiva conferencia "The danger of a single story" ha sido oída ya por casi doce millones de visitantes de la página web de TED. Adichie denuncia el orientalismo aún implícito en la consideración occidental de África y la alteridad que se practica indiscriminadamente y sin pararse a pensar. El consejo final de Adichie es claro: empecemos las narraciones con "Y en segundo lugar...", porque ser conscientes de que ha habido vida con anterioridad cambia por completo la historia. Esa vida la materializan las autoras, y la inscribió Adichie en sus novelas, Purple Hibiscus (2004), Half of a Yellow Sun (2006) y Americanah (2013).

Nuestra sociedad contemporánea está globalizada, para bien y para mal, y en ella, como hemos podido comprobar, hay lenguas dominantes que nos permiten enviar nuestro mensaje al mundo. Esto conlleva una gran paradoja, que no escribes para tu gente sino para ese "mundo" que, por otra parte, te desprecia. Se pregunta Amma Darko: "For whom do I write? Do I reach my target? Can I have the luxury of choosing a targer readership? Sometimes I feel like I write about the blind for the deaf" (Darko, 2009: n.p.). Esto produce una transculturación, que, en palabras de la poeta cubana Nancy Morejón, significa 
“[...] interacción constante, transmutación entre dos o más componentes culturales cuya finalidad inconsciente crea un tercer conjunto nuevo e independiente, aunque sus bases, sus raíces, descansen sobre los elementos precedentes. La influencia recíproca de cada componente es determinante" (1988: 188).

Este tercer conjunto debiera constituir una sociedad igualitaria, por tanto feminista y no racista, que siguiera los pasos del conocimiento democrático y de la diversidad cultural, y que no valorara a las personas por su sexo, por el color de su piel o por sus creencias o no creencias religiosas. Pero este tercer espacio de convivencia expresado por Morejón es, hoy por hoy, una utopía; se necesitarán muchas más autoras, muchas más voces ya despiertas a su subjetividad para cambiar tan radicalmente el paradigma de Género que nos estructura.

\section{BIBLIOGRAFÍA}

- Andreu, Cristina (1987): “An Interview with Lauretta Ngcobo". En: Universitas Tarraconensis, vol. XI, pp.193-200.

- de Beauvoir, Simone (1947): “The Ethics of Ambiguity". Disponible en: https://www.marxists.org/reference/subject/ethics/de-beauvoir/ambiguity/ [23/09/2014].

- Cushman, Donald P. y Branislaw Kovacic (1995) (eds.): Watershed Research Traditions in Human Communication Theory. New York: State University of New York Press.

- Darko, Amma [1991] (2003): Más allá del horizonte. Barcelona: El Cobre Ediciones. . (2007): Entrevista en el periódico Neue Zürcher Zeitung. 10 julio. (2009): Conferencia pronunciada el 17 de diciembre en la Universidad de Oviedo.

- Foucault, Michel [1969] (2002): La arqueología del saber. Buenos Aires: Siglo XXI editores.

- Grosz, Elizabeth (1990): "Inscriptions and Body-Maps: Representations and the Corporeal". En: Terry Threadgold y Anne Cranny-Francis (eds.): Feminine, Masculine, and Representation. Sydney: Allen\&Unwin, pp.62-74.

- Gunew, Sneja (1982): "Reading”. En: Anna Gibbs y Alison Tilson (eds.): Frictions. An Anthology of Fiction by Women. Melbourne: Sybilla Cooperative Press.

- Head, Bessie (1962): “Things I don't like”, poema. En The New African, vol.1, no. 7, July 1962. Disponible en: http://disa.ukzn.ac.za/sites/default/files/pdf_files/nafv1n7.jul62_8.pdf [30/03/2017].

- James, Adeola (1990): In There Own Voices. Londres: James Currey.

- Morejón, Nancy (1988): Fundación de la Imagen. La Habana: Editorial Letras Cubanas.

- Muana, Patrick (2008): “Ghanaian Novelist - Amma Darko”. En: MG Modern Ghana, 25 January. Disponible en: https://www.modernghana.com/lifestyle/237/ghanaian-novelist-ammadarko.html [18/01/2017]. 
- Ondaatje, Michael (1989): “Rock Bottom”. The Cinnamon Peeler. Londres: Pan Books.

- Quayson, Ato (2007): "Feminism, Postcolonialism and the Contradictory Orders of Modernity”. En: Tejunola Olaniyan y Ato Quayson (eds.): African Literature: An Anthology of Criticism and Theory. Oxford: Blackwell Publishing, pp. 585-591.

- Said, Edward [1993] (1994): Culture and Imperialism. Londres: Vintage Books.

- Tandon, Rajesh y Buddy Hall (2014): "Breaking down the knowledge walls". En: University World News, $\mathrm{n}^{\mathrm{o}}$. 448, 29 de Agosto de 2014. Disponible en: http://www.universityworldnews.com/article.php?story=20140826132652660 [02.03.2017].

- Teo, Thomas y Paul Mecheril (1994): Andere Deutsche. Zur Lebenssituation von Meschen multiethnischer und multikultureller Herkunft. Berlin: Dietz Verlag.

- Umezurike, Uchechukwu Peter (2015): "Resistance in Amma Darko's Beyond the Horizon y Chika Unigwe's On Black Sisters' Street”. En: Laligens, vol. 4, nº. 2, pp. 152-163.

- Vidal, María (1989): "Women Workers and Warriors in Bessie Head's Short Fiction”. En: BELLS, vol.1, pp. 225-234.

- Waldis, Barbara (1998): Trotz der Differenz. Interkulturelle Kommunikation bei maghrebinisch europäischen Paarbeziehungen in der Schweiz und in Tunesien. Münster: Waxmann Verlag. 